\title{
Zumbido Neurossensorial
}

\author{
Yotaka Fukuda*
}

\section{RESUMO}

Zumbido é uma sensação de som percebido pelo indivíduo na ausência de estímulo sonoro externo. Pode ser causado por estruturas contíguas à cóclea - zumbido periótico ou ser causado pela estrutura neuroepitelial auditiva - zumbido neurossensorial. O autor trata, neste artigo, sobre aspectos fisiopatológicos e etiopatogênicos do zumbido neurossensorial. Para estabelecer o diagnóstico, o aspecto mais importante é a anamnese detalhada, além da avaliação da audição. Estudos de imagem e exames laboratoriais podem ser úteis em certas situações. O tratamento deve ser feito individualmente, sendo ressaltada a importância da relação médico-paciente e o tratamento da causa. Medicamentos, equipamentos auxiliares e abordagens cirúrgicas podem ser necessários.

\section{UNITERMOS}

Zumbido, vertigem, disacusia neurossensorial.

\section{NTRODUÇÃO}

O zumbido é uma sensação de som percebido pelo indivíduo na ausência de estímulo sonoro externo. Pode ser periótico (ZPO) quando estruturas contíguas ou próximas à cóclea produzem o som, como a contração espontânea dos músculos do palato e da orelha média, a patência da tuba auditiva transmitindo o ruído da passagem do ar na nasofaringe e o zumbido pulsátil causado pela anomalia vascular no osso temporal. Esse tipo de zumbido (ZPO) cuja causa específica pode ser identificada com relativa facilidade, conhecendo-se a sua fisiopatologia e o seu tratamento, é relativamente raro. Por outro lado, o zumbido mais freqüente, que acomete um terço da população adulta, de diagnóstico e de solução mais difíceis, é o zumbido neurossensorial (ZNS) ${ }^{1}$, o qual iremos abordar neste artigo. Ele pode manifestar-se contínua ou intermitentemente, pode ser mono ou politonal, de baixa ou de alta freqüência e é relatado pelos pacientes como chiado, apito, cigarra, cachoeira, serra, rádio não-sintonizado, vento, onda do mar, etc. Na maioria das situações, não incomoda o paciente, porém pode ser manifestação inicial de um processo tumoral ou sistêmico; outras vezes é intolerável, havendo casos de tentativa de suicídio, tal o seu desconforto.

\section{ANATOMOFISIOLOGIA DO SISTEMA AUDITIVO}

A orelha interna (labirinto), onde é gerado o ZNS na maioria das vezes, é constituída pela cóclea, pelo vestíbulo utriculossacular e pelos canais semicirculares contidos na parte petrosa do osso temporal.

A cóclea é o órgão auditivo constituído por um tubo de parede óssea compacta (cápsula ótica), contendo no seu interior a perilinfa e a endolinfa, sendo esta última localizada na parte mais central da cavidade coclear e separada daquela por estrutura membranácea semipermeável. A perilinfa é o próprio líquido cefalorraquidiano que penetra no labirinto pelo aqueduto coclear e apresenta constituição iônica própria de líquido extracelular. A endolinfa é produzida por uma estrutura altamente diferenciada, a estria vascular, situada no interior da cóclea e que funciona como uma enorme bomba de sódio e potássio, removendo $\mathrm{Na}^{+}$constantemente para a entrada 
de $\mathrm{K}^{+}$, mantendo-o em alta concentração, semelhante à do líquido intracelular, fundamental para geração de potencial endococlear.

O órgão de Corti é constituído pelas células neuroepiteliais auditivas (células ciliadas internas e externas, células de sustentação e membrana tectória) e está situado no interior da estrutura membranácea, porém banhado pela perilinfa.

A energia sonora vibratória, chegando às células ciliadas, causa pressão sobre os cílios das células, abrindo canais iônicos para entrada de $\mathrm{K}^{+}$e $\mathrm{Ca}^{++}$no seu interior, sendo o potencial endococlear necessário para passagem desses íons. A entrada de $\mathrm{Ca}^{++}$desencadeia geração de potências intracelulares que estimulam a liberação de neurotransmissores nas células ciliadas e posterior formação de potencial de ação pós-sináptico no nervo coclear. O gânglio espiral constitui a primeira ordem de neurônios auditivos e está situado no modíolo, que é o eixo central ósseo da cóclea. Esses neurônios emitem expansões distais que fazem sinapse com as células ciliadas e, proximalmente, os seus axônios vão formar o ramo coclear do nervo vestibulococlear. O potencial de ação do nervo coclear chega ao tronco encefálico (aos núcleos cocleares, ao complexo olivar, ao colículo inferior) e ao corpo geniculado medial atingindo o córtex cerebral no giro temporal transverso anterior, situado ao longo do sulco lateral, onde há reconhecimento do som. Porém, para haver efetivo reconhecimento do som e sua posterior memorização, outras funções mentais são acionadas, determinando o grau de importância de um estímulo sonoro específico.

\section{FISIOPATOLOGIA DO ZNS}

Qualquer distúrbio no funcionamento do sistema auditivo, desde os cílios da célula sensorial até o córtex auditivo, pode gerar atividade elétrica espúria que pode ser percebida como som. Alteração na relação mecânica do sinal sonoro que pressiona o cílio da célula, causando distúrbio no canal iônico, agressão na membrana das células neuroepiteliais, catabólitos não adequadamente eliminados pelo sistema reticuloendotelial das células receptoras da energia sonora, modificação na quantidade e na velocidade de formação, liberação e inativação dos neurotransmissores e deterioração da bainha de mielina são alguns dos fenômenos que podem gerar zumbido ${ }^{2}$. Essa atividade elétrica anômala, gerada endogenamente, na ausência de estímulo sonoro externo, acarreta o ZNS, que, interagindo com outras funções mentais, como memória e emoção, atinge a via final comum, determinando a sua nocicepção.
Essas alterações iniciam-se em sua grande maioria nas células sensoriais da cóclea, porém a disfunção não fica confinada somente nessas estruturas, afetando centripetamente as estruturas proximais. Por exemplo, a destruição da célula ciliada acarreta alteração na relação sináptica com neurônio do gânglio espiral, com sua conseqüente disfunção, que, por sua vez, pode alterar o funcionamento do núcleo coclear e assim por diante, até o córtex auditivo cerebral. Essa disfunção na neurotransmissão pode iniciar-se em qualquer ponto da via auditiva, e não apenas nas células receptoras, e pode causar também disacusia ${ }^{3}$.

\section{ETIOPATOGENIA DO ZNS}

Todo e qualquer agente agressor que determina mau funcionamento do sistema auditivo pode gerar zumbido. As causas mais freqüentes são descritas a seguir.

- Trauma acústico. As delicadas estruturas neurossensoriais da cóclea estão dimensionadas para receber energia sonora produzida pela natureza, que raramente excede os $90 \mathrm{~dB}$. O homem foi gradual e continuamente produzindo artefatos cada vez mais potentes e ruidosos que excedem o tolerado pela orelha humana, lesando as estruturas neuroepiteliais auditivas. Se essa lesão for pequena, poderá ser reversível, porém, à medida que essa exposição se tornar mais intensa e duradoura, mais estruturas sofrerão alterações que poderão ser irreversíveis, acarretando zumbido permanente e perda auditiva neurossensorial que se iniciam nas freqüências de 4 e $6 \mathrm{kHz}$.

- Substâncias ototóxicas. Diversas drogas, como antibióticos aminoglicosídicos, alguns antiinflamatórios não-hormonais, cardiotônico digitálico, diuréticos como ácido etacrícrino e furosemida, antineoplásico, principalmente à base de cisplatina, antimaláricos, como quinino, são agentes agressores das células ciliadas auditivas. Substâncias como mercúrio e chumbo são também lesivas à cóclea.

- Traumas craniano e cervical. O impacto da cabeça contra uma superfície rígida pode causar abalo nas estruturas do órgão de Corti o suficiente para levar ao distúrbio de seu funcionamento. Trauma mais intenso pode acarretar fratura do osso temporal, atingindo o labirinto. Nesses casos, há intensa degeneração do órgão de Corti, geralmente com zumbido, às vezes insuportável, em decorrência da lesão no botão sináptico. A secção 
do nervo coclear nem sempre é efetiva. O implante coclear é um procedimento que pode ser útil para combater o zumbido nos casos mais problemáticos.

O trauma cervical mais freqüente é o contragolpe nos impactos frontais de veículos, em que a cabeça é lançada para frente e a seguir para trás abruptamente, com alterações cervicais mioneurovasculares, com repercussão sobre o labirinto.

- Fístula perilinfática. As janelas oval e redonda são locais frágeis na cápsula ótica e suas membranas podem romper-se por variação brusca na pressão intralabiríntica ou por algum trauma, com saída de perilinfa. Esse extravasamento causa distúrbio hidrodinâmico e bioquímico da orelha interna com lesão das estruturas neuroepiteliais, levando à surdez súbita, ao zumbido e à vertigem. A oclusão precoce da fístula restaura o equilíbrio e a audição; quanto ao zumbido, raramente há supressão dessa manifestação, porém há um alívio em grau variado.

- Distúrbio metabólico e endócrino. A estria vascular despende enorme quantidade de energia (ATP) para manter sempre alta a concentração de $\mathrm{K}^{+}$na endolinfa, havendo intensa atividade de $\left(\mathrm{Na}^{+} \mathrm{K}^{+}\right)$ATPase. Como não há reserva de glicogênio na cóclea, há necessidade de contínuo e regular aporte de substrato energético. Altas concentrações de insulina sangüínea diminuem a atividade de $\left(\mathrm{Na}^{+} \mathrm{K}^{+}\right)$ATPase com conseqüente retenção de $\mathrm{Na}^{+}$na endolinfa, que, por sua vez, acarreta diminuição do potencial endococlear e aumento da pressão osmótica nesse espaço, causando disfunção no órgão de Corti. Endocrinopatias como alterações tiroideanas, tanto a hiper como a hipofunção, assim como alterações ovarianas e hipofisárias, também podem causar zumbido.

- Otospongiose coclear. A otospongiose é um distúrbio no processo de formação, organização e absorção da cápsula ótica, apresentando inicialmente intensa atividade osteoclástica e osteoblástica e posterior calcificação. Essa grande atividade óssea causa distúrbio vascular e liberação de catabólitos na perilinfa, que podem ser lesivos às células neuroepiteliais do labirinto, originando zumbido, tontura e disacusia neurossensorial (DNS) 4 .

- Infecção. Qualquer infecção viral sistêmica pode causar danos ao órgão de Corti, sendo as mais frequientes a rubéola materna, o citomegalovírus, a parotidite epidêmica e o herpes zoster oticus. Quanto às bacterianas, as causadoras de meningite, de otite média aguda, de otite externa maligna e de otite tuberculosa podem lesar a orelha interna.

- Processo alérgico. Os processos imunes mediados mais freqüentes são os alérgicos e podem comprometer o labirinto, cuja manifestação maior é a vertigem, porém também podem levar à DNS e ao ZNS. História detalhada pode fornecer dados importantes sobre o agente causal, assim como os testes específicos.

- Schwannoma vestibular. Tanto a compressão do nervo coclear como da artéria labiríntica (ramo da artéria cerebelar anterior inferior) levam à hipoxia da orelha interna, causando transtorno do órgão de Corti e do nervo vestibulococlear com sintoma inicial de zumbido e hipoestesia facial.

- Alterações centrais. Acometimento das vias auditivas por processos degenerativos, como esclerose múltipla e doença de Alzheimer, doenças tumorais e vasculares, podem causar transtornos na neurotransmissão auditiva gerando zumbido.

\section{AVALIAÇÃO DO ZNS}

Os dados mais importantes são obtidos pela anamnese, como início, duração, característica do ZNS (tonalidade, intensidade, evolução), topografia (uni ou bilateral, no ouvido, na cabeça), fatores de melhora ou de piora, grau de incômodo e possível relação de causa e efeito.

O exame físico geral deve incluir a aferição do peso corporal, da pressão arterial e da ausculta cardíaca. O exame otorrinolaringológico, com acurada avaliação otoscópica do meato acústico externo e da membrana do tímpano, deve ser realizado. O exame da articulação temporomandibular, incluindo a palpação dos seus músculos e ligamentos, deve ser incluído.

A audiometria tonal liminar, não só nas freqüências convencionais (de $250 \mathrm{~Hz}$ a $8 \mathrm{kHz}$ ), mas também nas altas freqüências (até $16 \mathrm{kHz}$ ), e a audiometria vocal são exames imprescindíveis à avaliação da audição.

A imitanciometria, englobando a timpanometria e a medida do reflexo estapediano, assim como a emissão otoacústica, a audiometria eletrofisiológica, a mensuração do zumbido quanto à intensidade e à tonalidade $\mathrm{e}$ 
o exame vestibular devem ser realizados de acordo com o quadro. A sensibilidade do nervo facial deve ser avaliada em todos os casos de ZNS unilateral.

Os estudos de imagem, como a ultra-sonografia cervical, a tomografia computadorizada do osso temporal e do pescoço, a ressonância magnética e a angiografia digital são exames seletivos que devem ser realizados de acordo com a suspeita diagnóstica de cada caso. Por exemplo, a tomografia computadorizada para estudo da cápsula ótica na suspeita de otospongiose coclear, ou a ressonância magnética com contraste na suspeita de schwanoma vestibular deve ser providenciada.

Exames laboratoriais específicos devem ser solicitados apenas para esclarecimento específico, como dosagem da insulina no sangue nos casos sugestivos de ZNS por distúrbio metabólico ou estudos imunoistoquímicos anticocleares nos casos de ZNS autoimune.

\section{TRATAMENTO DO ZNS}

\section{Aspecto geral}

A atenção dispensada e o interesse demonstrado na elucidação do caso ${ }^{4}$ estabelecem empatia e inspiram confiança ao paciente, fundamentais ao bom resultado. Aspecto nutricional, obesidade, hipertensão arterial, aspecto emocional, atividade física, qualidade do sono, doenças sistêmicas e medicamentos em uso devem ser observados e corrigidas as suas alterações. Café, cigarro e álcool devem ser restringidos.

\section{Tratamento etiológico}

O combate à causa do zumbido é a maneira mais efetiva de suprimi-lo ou controlá-lo. A oclusão precoce da fístula perilinfática, a exérese de tumor vestibular, a identificação e a suspensão de droga ototóxica são exemplos do enfoque etiológico.

\section{Tratamento medicamentoso}

Se o cuidado geral não for suficiente, o uso de medicamento pode propiciar algum grau de alívio ao paciente. Em casos agudos e recentes de ZNS por trauma craniano ou trauma acústico, o corticosteróide (prednisona $1 \mathrm{mg} / \mathrm{kg} / \mathrm{dia}$ ) e a pentoxifilina $400 \mathrm{mg}, 2$ vezes/ dia, podem ser úteis. Nos processos crônicos, como nas seqüelas ao uso de droga ototóxica, às infecções e aos traumas, pode-se administrar antagonista de cálcio (cinarizina $12,5 \mathrm{mg}$, três vezes ao dia; flunarizina 10 $\mathrm{mg}$, uma a duas vezes ao dia) ou o extrato de gingkobiloba $80 \mathrm{mg}$ ao dia. Nos casos em que o zumbido é mais incômodo à noite, perturbando o sono, o clonazepam $0,25 \mathrm{mg}$ a $0,5 \mathrm{mg}$ ao deitar pode reduzir o sintoma e permitir um sono mais tranqüilo. A administração intratimpânica de corticosteróide ou gentamicina pode ser útil em alguns casos.

\section{Aparelhos auxiliares}

A prótese de amplificação sonora está indicada nos casos em que também há hipoacusia; o mascarador de zumbido, equipamento que gera som semelhante ao zumbido, pode tornar a manifestação mais tolerável.

$\mathrm{O}$ estimulador elétrico tanto extracoclear ${ }^{5}$ como intracoclear ${ }^{6}$ exige intervenção cirúrgica e deve ser reservado àqueles casos em que outros métodos não foram suficientes no controle do zumbido.

\section{Tratamento cirúrgico}

A labirintectomia e a secção do nervo coclear devem ser reservadas para os casos em que houver anacusia e o zumbido permanecer intolerável.

\section{Tratamento alternativo}

A acupuntura realizada por otorrinolaringologista pode fornecer alívio ao zumbido. $\mathrm{O}$ auto-relaxamento pela identificação da tensão muscular cervical também pode ser útil desde que realizado adequadamente.

\section{COMENTÁRIO FINAL}

O ZNS pode ter inúmeras causas e diversos fatores concorrem para agravá-lo. Deve o médico procurar avaliar holisticamente, valorizando a informação do paciente e procurando estabelecer a causa do zumbido e a maneira mais adequada ao tratamento. Não abandonar o paciente à própria sorte, pois, se muitas vezes não há meios para supressão do zumbido, podese atenuá-la e só o fato de o paciente poder contar com o apoio, o esclarecimento e as orientações médicas já é de grande auxílio para enfrentar o desconforto, o sofrimento e a angústia causados por essa manifestação. 


\section{SUMMARY}

\section{Neurosensorial Tinnitus}

Tinnitus is defined as a sound sensation perceived without an external stimulus. It can be caused by structures near the cochlea (periotic tinnitus) or can be caused by auditory neuroepithelial structures (neurossensorial tinnitus). The author describes the physiopatology and the pathogenesis of neurosensorial tinnitus. In order to establish the diagnosis, careful history and audiometric evaluation must be done. Image studies of the temporal bone and laboratory analysis may be useful. Close relationship between the patient and the physician is fundamental to the success of treatment The cause of tinnitus must be identified and treated in order to have an effective result. Drugs, specific equipments or surgical procedure may be necessary in some circumstances.

\section{KEYWORDS}

Tinnitus, vertigo, hearing loss.

\section{Referências}

1. Fukuda Y. Surdezes de origem metabólica, vascular e autoimune. Zumbidos. In: Hungria, H. Otorrinolaringologia. $8^{a}$ edição. Rio de Janeiro. Ed. Guanabara-Koogan, 2000, p. 460-466.
2. Sanchez TG. Zumbido. Estudo da correlação entre limiar tonal e eletrofisiológico e das respostas elétricas do tronco cerebral. [Tese de doutorado]. USP-SP. 1997.

3. Shulman A. Tinnitus models: a basis for the evaluation of the pathophysiology of tinnitus. In: Shulman A, Aran JM, Tonndorf J, Feldmann H, Vernon JA. Tinnitus. Diagnosis/ treatment. Editora Lea \& Febiger Philadelphia, 1991, p. 6798.

4. Nodar RH. "CAPPE" - A strategy for counseling tinnitus patients. Inter Tinnitus J, 2(2):111-3, 1996.

5. Matsushima J, Sakail N, Takeishi N, Kobayashi Y, Mioshi S, Sakajiri M, Ikufube T. Surgical method for implanted tinnitus supressor. Inter Tinnitus J, 2:21-5, 1996.

6. Fukuda $\mathrm{Y}$, Mangabeira-Albernaz PL. The AllHear coclear implant and tinnitus. Inter Tinnitus J, 4(2):159-61, 1998.

Endereço para correspondência:

Prof. Dr. Yotaka Fukuda

Rua Silvia, 276

CEP 01331-010 - São Paulo, SP

Tel.: (0XX11) 253-6611

E-mail: fukuda.otor@epm.br 